Communication

\title{
3D nanoporous iridium-based alloy microwires for efficient oxygen evolution in acidic media
}

\author{
Yang Zhao ${ }^{\mathrm{a}}$, Min Luo ${ }^{\mathrm{b}}$, Shufen $\mathrm{Chu}^{\mathrm{c}}$, Ming Peng ${ }^{\mathrm{a}}$, Boyang Liu ${ }^{\mathrm{d}}$, Qiuli Wu ${ }^{\mathrm{a}}$, Pan $\mathrm{Liu}^{\mathrm{c}}$, \\ Frank M.F. de Groot ${ }^{\mathrm{e}}$, Yongwen Tan ${ }^{\mathrm{a}, *}$ \\ ${ }^{a}$ College of Materials Science and Engineering, Key Laboratory for Micro-Nano Physics and Technology of Hunan Province, Hunan University, Changsha, Hunan 410082, \\ China \\ ${ }^{\mathrm{b}}$ Department of Physics, Shanghai Polytechnic University, Shanghai 201209, China \\ ${ }^{\mathrm{c}}$ State Key Laboratory of Metal Matrix Composites, School of Materials Science and Engineering, Shanghai Jiao Tong University, Shanghai 200030, China \\ ${ }^{\mathrm{d}}$ Department of Physics, AlbaNova University Center, Stockholm University, S-10691 Stockholm, Sweden \\ ${ }^{\mathrm{e}}$ Inorganic Chemistry \& Catalysis, Debye Institute for Nanomaterials Science, Utrecht University, Universiteitsweg 99, 3584 CG Utrecht, Netherlands
}

\section{A R T I C L E I N F O}

\section{Keywords:}

Nanoporous

Alloy

Dealloying

Oxygen evolution reaction

Acidic media

\begin{abstract}
A B S T R A C T
Although significant progresses have been achieved recently in developing catalysts for electrochemical oxygen evolution in alkaline electrolytes, high performance catalysts toward oxygen evolution in acidic media have not been realized in spite of the technical importance for the development of promising energy transformation technologies including electrocatalytic water splitting, integrated (photo)electrochemistry cells, rechargeable metal-air batteries, and so on. Here, we synthesized a three-dimensional nanoporous $\operatorname{Ir}_{70} \mathrm{Ni}_{30-\mathrm{x}} \mathrm{Co}_{\mathrm{x}}$ alloy microwires as oxygen evolution reaction electrocatalyst using a dealloying strategy. The three dimensional binderfree np- $\mathrm{Ir}_{70} \mathrm{Ni}_{15} \mathrm{Co}_{15}$ catalyst in $0.1 \mathrm{M} \mathrm{HClO}_{4}$ shows a low overpotential $\left(220 \mathrm{mV} @ \eta=10 \mathrm{~mA} \mathrm{~cm}{ }^{-2}\right)$, low Tafel slope (44.1 $\mathrm{mV} \mathrm{dec}^{-1}$ ) and excellent corrosion resistance, significantly outperforming commercial $\mathrm{IrO}_{2}$ catalysts. The excellent performance is attributed to the nanoporous structure and the alloying effect, which promote the permeation of electrolyte, accelerate the transportation of electrons. More importantly, the high valence Ir oxide species with low-coordination structure in $n p-\mathrm{Ir}_{70} \mathrm{Ni}_{15} \mathrm{Co}_{15}$ alloy are identified for the real catalytic sites of OER process by the XAS results acquired on synchrotron radiation. This work not only provides fundamental understandings of the correlation between surface activity and stability for OER catalysts, but also paves a new way to advanced electrocatalysts working in acidic media.
\end{abstract}

\section{Introduction}

The oxygen evolution reaction (OER) is a critical anodic process in electrochemical water splitting and rechargeable metal-air batteries [1]. Although recent reported electrocatalysts have shown enhanced performance toward electrochemical water splitting [2-5], OER electrocatalysts suffer significantly from sluggish kinetics and/or low stability in acidic electrolytes. The low efficiency mainly results from the sluggish multi-proton coupled electron transfer to the oxygen intermediate species over the catalyst surface [6-8]. Though the acid environment with high proton conductivity and high-grade purity is favorable for OER [9], most recent electrocatalysts are not stable under strong acidic conditions [10]. Thus, developing efficient electrocatalysts for low $\mathrm{pH}$ environment is a still a challenge. The low-abundance Ir-based systems are known to be the best OER catalysts in acidic media [11]. Although, many efforts have focused on the designing and engineering of Ir-based OER catalysts by modifying morphologies or compositions. For example, Ir-based nanoclusters [12], Co-doped $\mathrm{IrCu}$ alloys [13], IrNi oxides [14], Ir-based nanoframes [15] have been reported recently, most researches are focused on Ir-based nanoparticles (NPs) or some irregular materials by wet chemical synthesis, but the surfactants attached on the surface of the catalysts not easy to remove [16]. Furthermore, these Ir-based catalysts are usually pasted on carbon supports by addition of binding materials (e.g. Nafion), which could suffer serious corrosion in harsh acidic electrolytes, resulting in poor stability in long-term OER process [17]. Thus, the facile and controllable synthesis of surfactant-free, ultrafine, and self-supported threedimensional (3D) Ir-based alloyed electrocatalysts via a simple, inexpensive, and scalable approach, is extremely desirable for efficient electrocatalytic oxygen evolution.

\footnotetext{
* Corresponding author.

E-mail address: tanyw@hnu.edu.cn (Y. Tan).
} 

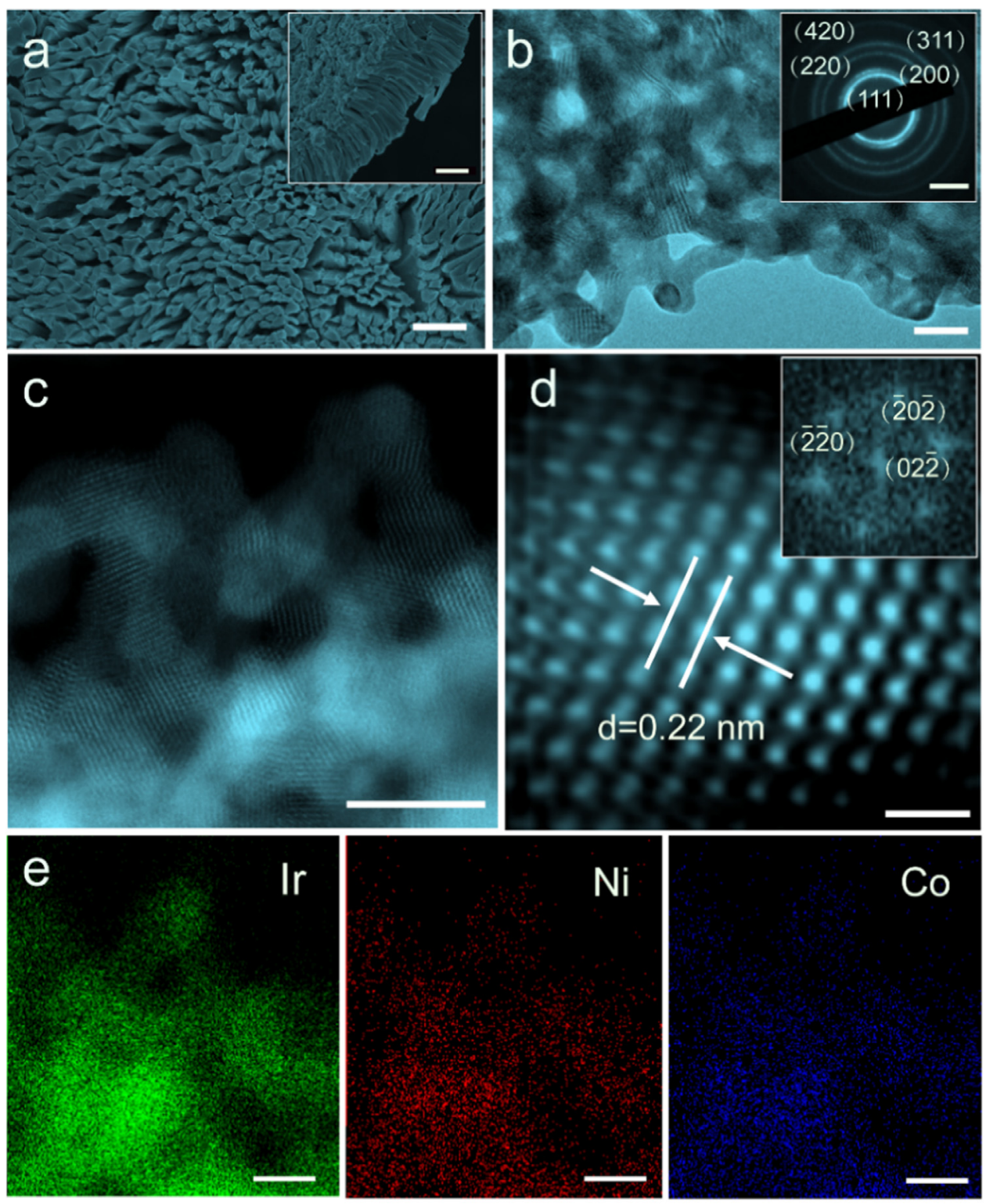

Fig. 1. Structural and composition characterizations of the $n p-\mathrm{Ir}_{70} \mathrm{Ni}_{15} \mathrm{Co}_{15}$ MWs. (a) SEM image, inset is the cross-section morphology. (b) TEM image and corresponding SAED pattern. (c) HAADF-STEM images. (d) Fast Fourier transformation (FFT) filtered HAADF-STEM image and corresponding FFT pattern. (e) STEMEDS mapping of Ir (green), Ni (red), and Co (blue). Scale bars: (a) $3 \mu \mathrm{m}$, inset: $2 \mu \mathrm{m}$, (b) $10 \mathrm{~nm}$, inset: $1 / 5 \mathrm{~nm}$, (c) $5 \mathrm{~nm}$, (d) $0.5 \mathrm{~nm}$, and (e) $5 \mathrm{~nm}$.

Among many synthesis methods that have been developed for 3D self-supported electrocatalyst, such as galvanic replacement [18], template assisted [19], hydrothermal [20], and dealloying [21]. Dealloying is a selective electrochemical dissolution process of less noble component from the mother alloy, while the retained noble metal form a 3D bicontinuous nanoporous (np) architectures by interfacial selfassembly and self-diffusion [22,23]. Bi- or multi-metallic nanoporous metals, especially Au, Pd and Pt-based alloys, are extensively synthesized by utilizing this approach to improve catalytic activities toward the molecular oxidation/reduction reaction [24,25]. These alloys with bicontinuous pores provide efficient mass diffusion and allow more accessible interior active sites. Moreover, the interconnected ligaments offer free paths for fast electron transfer. Besides, the self-supported 3D skeleton could withstand the corrosion problems during long-term catalysis process under the harsh acidic environment [26]. Therefore, rationally designed nanoporous Ir-based alloys with multiple redoxactive metals are expected to be a promising approach of boosting efficient and durable OER catalysts due to the integration of advantageous hybrid porous architectures, free-standing interconnected structures, and synergistic interactions of alloying.

Herein, we present a facile, one-step dealloying synthetic route to prepare multimetallic $\operatorname{Ir}_{70} \mathrm{Ni}_{30-\mathrm{x}} \mathrm{Co}_{\mathrm{x}}(\mathrm{x}=0,15,30)$ microwires (MWs) with ultrafine nanoporous structure. The $3 \mathrm{D}$ binder-free nanoporous $\mathrm{Ir}_{70} \mathrm{Ni}_{15} \mathrm{Co}_{15}$ catalyst exhibits highly efficient and stable OER electrocatalytic activity with overpotential of $220 \mathrm{mV}$ at a current density of $10 \mathrm{~mA} \mathrm{~cm}^{-2}$ and Tafel slope around $44.1 \mathrm{mV} \mathrm{dec}^{-1}$ in acidic electrolyte. These extraordinary catalytic activities toward acidic water splitting have not been achieved from many other state-of-the-art OER electrocatalysts before.

\section{Experimental section}

\subsection{Synthesis of precursor $\mathrm{Ir}_{3} \mathrm{Ni}_{97-x} \mathrm{Co}_{x}$ ribbons}

The $\mathrm{Ir}_{3} \mathrm{Ni}_{97-\mathrm{x}} \mathrm{Co}_{\mathrm{x}}(\mathrm{x}=0,50,97)$ alloy ingot was prepared by arc melting under an argon atmosphere. A melt spinning technique was introduced to rapidly quench the re-melt the alloy ingots by the cold surface of a spinning copper roller to achieve a homogeneous 

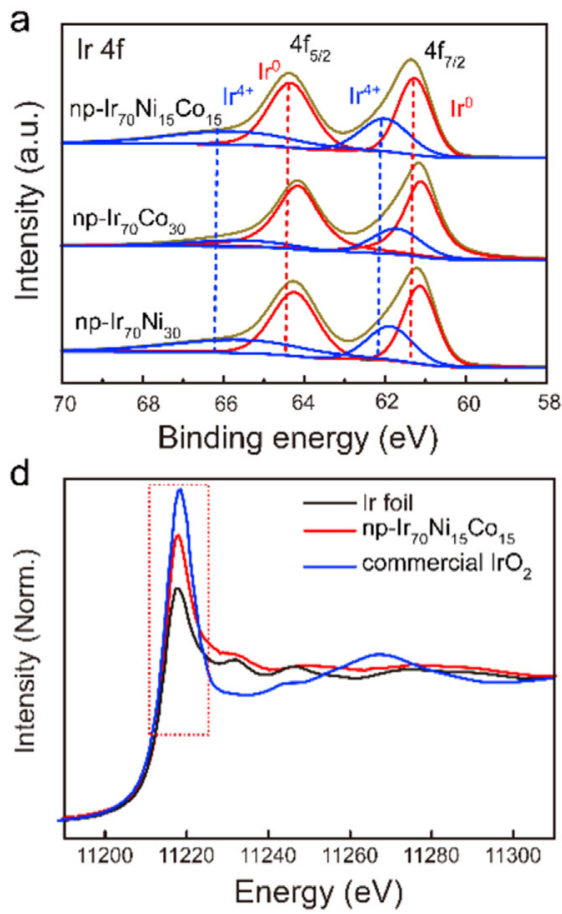

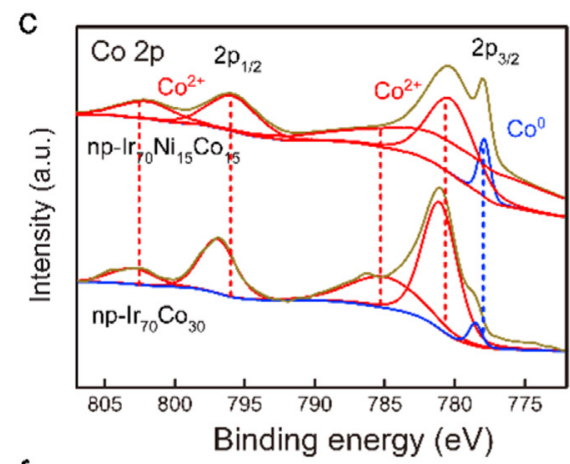

$f$

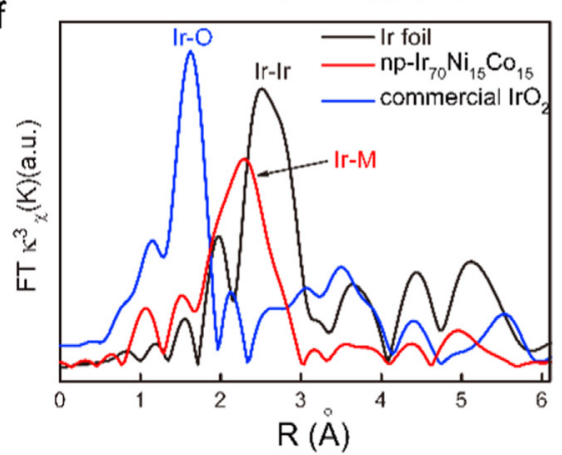

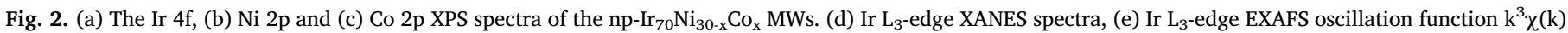
and (f) the corresponding Fourier transforms of Ir $\mathrm{L}_{3}$-edge EXAFS spectra for np- $\mathrm{Ir}_{70} \mathrm{Ni}_{15} \mathrm{Co}_{15}$ and the standard reference Ir foil and IrO $\mathrm{O}_{2}$.

nanocrystalline single-phase ribbons with the dimensions of $\sim 2 \mathrm{~mm}$ wide and $30 \mu \mathrm{m}$ thick. The ribbons were cut into thin plates with dimensions of $2 \mathrm{~mm}$ wide and $10 \mathrm{~mm}$ length for the fabrication of nanoporous $\mathrm{Ir}_{70} \mathrm{Ni}_{30-\mathrm{x}} \mathrm{Co}_{\mathrm{x}}(\mathrm{x}=0,15,30)$ catalysts.

\subsection{Synthesis of $n p-I r_{70} \mathrm{Ni}_{30-x} \mathrm{Co}_{x} \mathrm{MWs}$}

The $n p-\mathrm{Ir}_{70} \mathrm{Ni}_{30-\mathrm{x}} \mathrm{Co}_{\mathrm{x}}(\mathrm{x}=0,15,30)$ MWs catalysts were fabricated by electrochemically etching the single-phase $\operatorname{Ir}_{3} \mathrm{Ni}_{97-\mathrm{x}} \mathrm{Co}_{\mathrm{x}}(\mathrm{x}=0,50$, 97) precursors in a $0.25 \mathrm{M} \mathrm{HCl}$ solution using an electrochemical workstation (CHI 760e) in a standard a standard three-electrode configuration with a $\mathrm{Ag} / \mathrm{AgCl}$ electrode as the reference electrode and a graphite sheet as the counter electrode. The dealloying current gradually decreases with the dealloying time at a designed potential. We set up a current threshold of $1 \mathrm{~mA} \mathrm{~cm}{ }^{-2}$ to terminate the dealloying instead of time and etching depth. The dealloyed samples were rinsed by deionized water for more than three times to remove the residual chemical substances within nanopore channels.

\subsection{Characterization}

X-ray diffraction (XRD) patterns of the samples were taken by using a Bruker D8 Advance X-ray diffraction with $\mathrm{Cu}$ Ka radiation $(\lambda=1.5418 \AA$ ). Microstructure and chemical composition were inspected with a Zeiss Sigma HD SEM (at $10 \mathrm{kV}$ and $8.5 \mathrm{~mm}$ work distance.) equipped with an Oxford energy dispersive X-ray spectroscopy. The transmission electron microscopy (TEM), high-angle annular dark field-scanning TEM (HAADF-STEM) and energy dispersive X-ray spectroscopy (EDS) mapping were taken by a JEM-ARM $200 \mathrm{~F}$ with double spherical aberration (Cs) correctors for both the probe-forming and image-forming objective lenses at an accelerating voltage of $200 \mathrm{kV}$. The chemical state and composition of the samples were characterized using X-ray photoelectron spectroscopy (XPS, Thermo Scientific Escalab 250Xi) with a $\mathrm{Al} \mathrm{Ka}$ monochromatic ( $150 \mathrm{~W}, 20 \mathrm{eV}$ pass energy, $500 \mu \mathrm{m}$ spot size). The specific surface area was obtained from the results of $\mathrm{N}_{2}$ physisorption at $77 \mathrm{~K}$ (Micromeritics ASAP 2020) by using the BET (Brunauer-Emmet-Teller). The content of Ir, Ni and Co were obtained via the inductively coupled plasma-optical emission spectrometer (ICPOES) (Agilent 730). X-ray absorption spectra, including the X-ray absorption near-edge structure (XANES) and extended X-ray absorption fine structure (EXAFS), were obtained at the $\mathrm{Ir} \mathrm{L}_{3}$-edge, Ni K-edge and Co K-edge at the beamline 01C1 (National Synchrotron Radiation Research Center: NSRRC, Hsinchu, Taiwan). All spectra were obtained in the fluorescence mode at room temperature.

\subsection{Electrochemical measurements}

The electrochemical performances of the samples were investigated using an $\mathrm{CHI760e}$ electrochemical workstation in a three-electrode system, where the $\mathrm{np}-\mathrm{Ir}_{70} \mathrm{Ni}_{30-\mathrm{x}} \mathrm{Co}_{\mathrm{x}}$ direct used as the working electrode, graphite electrode and $\mathrm{Ag} / \mathrm{AgCl}$ electrode were used as the counter electrode and reference electrode. $0.1 \mathrm{M} \mathrm{HClO}_{4}, 1.0 \mathrm{M} \mathrm{KOH}$ and $1.0 \mathrm{M}$ phosphate buffered solutions (PBS) were served as the acidic, alkaline and neutral electrolytes, respectively. All applied potentials were converted with respect to reversible hydrogen electrode (RHE), $\mathrm{E}_{\mathrm{RHE}}$ $=\mathrm{E}_{\mathrm{Ag} / \mathrm{AgCl}}+0.0591 \mathrm{pH}+0.197 \mathrm{~V}$, and the overpotential $(\eta)$ for OER was calculated using the following equation: $\eta=E_{\mathrm{RHE}}-1.23 \mathrm{~V}$.

Polarization curves were obtained by linear sweep voltammetry (LSV) with a scan rate of $2 \mathrm{mV} \mathrm{s}^{-1}$ and corrected by iR compensation. Before the LSV measurement, the catalyst was conducted to a number of cyclic voltammetry (CV) cycles at a scan rate of $50 \mathrm{mV} \mathrm{s}^{-1}$ until a stable CV curve was obtained. The current densities (j) were based on geometric areas. Electrochemical impedance spectroscopy (EIS) plots were performed in the frequency range of $0.01-10^{6} \mathrm{~Hz}$ with operating voltage at $1.45 \mathrm{~V}$ vs RHE. The Tafel plots were derived from the LSV curves and calculated based on the equation $\eta=b * \log j+a$, where $b$ and $j$ are the Tafel slope and current density, respectively. The electrochemical active surface areas (ECSA) were determined by taking CV measurement in acidic electrolyte with scan rates ranging from 10 to $50 \mathrm{mV} \mathrm{s}^{-1}$ with an interval point of $10 \mathrm{mV} \mathrm{s}^{-1}$. The double layer capacitance $\left(\mathrm{C}_{\mathrm{dl}}\right)$ was calculated by plotting the charge current density differences $\left(\Delta \mathrm{j}=\mathrm{j}_{\text {anodic }}-\mathrm{j}_{\text {cathodic }}\right)$ at middle potential windows against the scan rate. The slope of the fitting line is equal to twice of the $C_{\mathrm{d}}$. The $\mathrm{C}_{\mathrm{S}}$ was estimated according to our previous work [21], ECSA was calculated by 
a

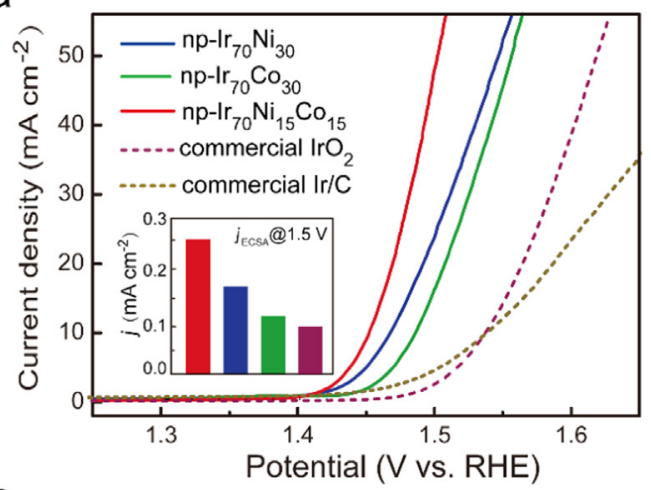

C

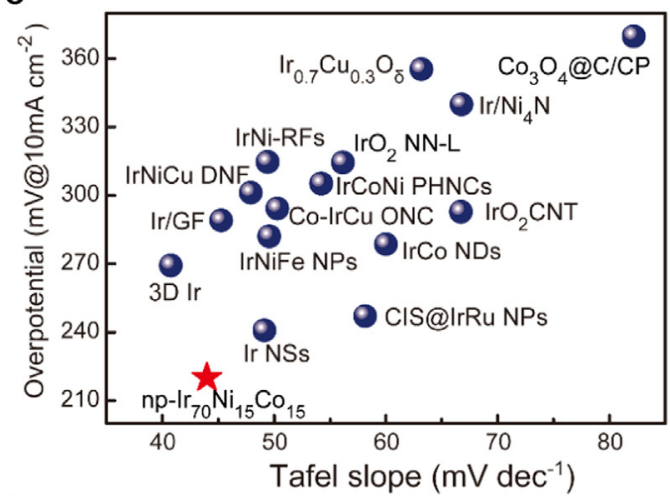

e

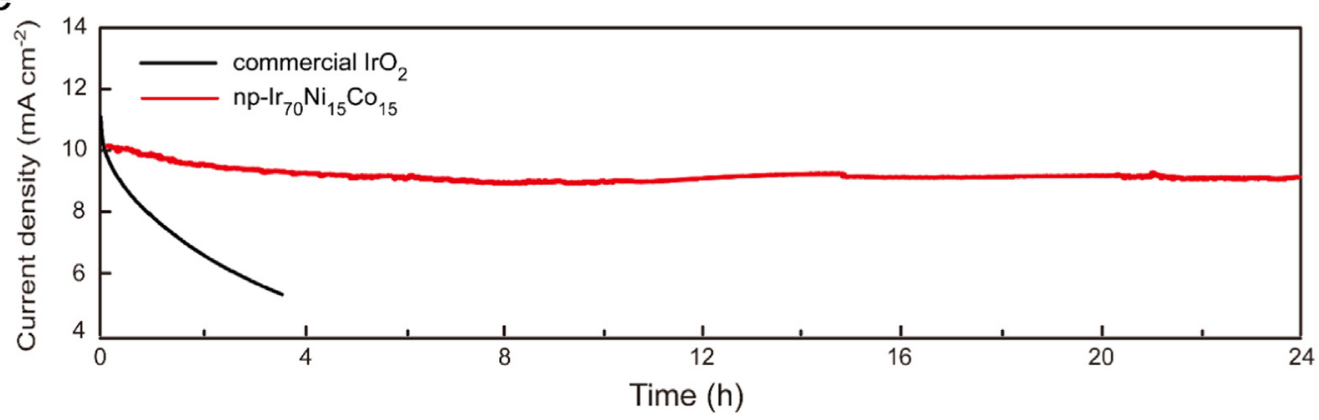

$b$

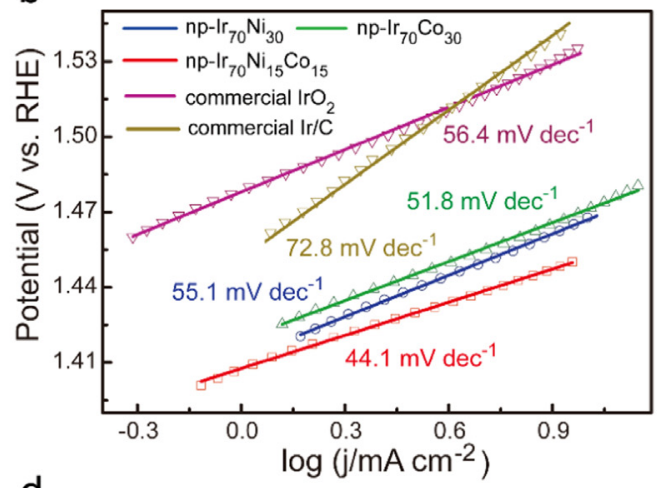

d

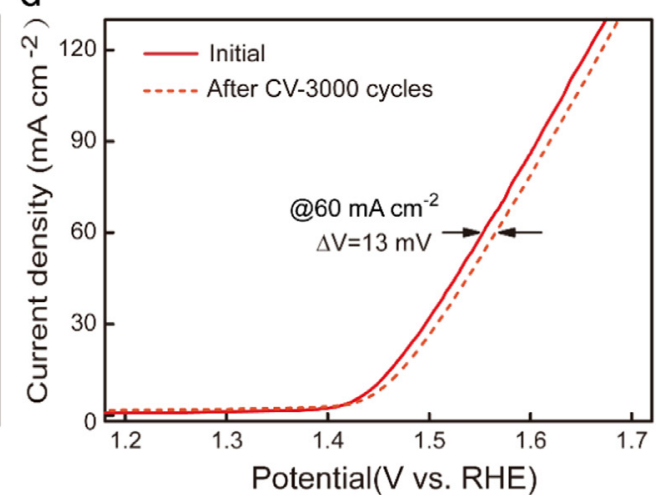

Fig. 3. Electrochemical characterizations of the commercial $\mathrm{IrO}_{2}$, np$\mathrm{Ir}_{70} \mathrm{Ni}_{30}$, np- $\mathrm{Ir}_{70} \mathrm{Co}_{30}$, and np$\mathrm{Ir}_{70} \mathrm{Ni}_{15} \mathrm{Co}_{15}$ in acidic electrolyte. (a) Polarization curves. Inset shows comparison of the specific activity at an overpotential of $270 \mathrm{mV}$ for the commercial $\mathrm{IrO}_{2}$ (purple), $\mathrm{np}-\mathrm{Ir}_{70} \mathrm{Ni}_{30}$ (blue), np- $\mathrm{Ir}_{70} \mathrm{Co}_{30}$ (green), and np$\mathrm{Ir}_{70} \mathrm{Ni}_{15} \mathrm{Co}_{15}$ (red) electrocatalysts. (b) the corresponding Tafel plots. (c) The comparison of both kinetics (Tafel slope) and activity (the overpotential required to achieve $10 \mathrm{~mA} \mathrm{~cm}^{-2}$ ) with references all measured for OER in acidic electrolyte. (d) OER polarization curves of $\mathrm{np}-\mathrm{Ir}_{70} \mathrm{Ni}_{15} \mathrm{Co}_{15}$ and durability test after 3000 cycles. (e) Current-time chronoamperometric response of self-supported np$\mathrm{Ir}_{70} \mathrm{Ni}_{15} \mathrm{Co}_{15}$ (at $1.45 \mathrm{~V}$ ) and commercial $\mathrm{IrO}_{2}$ catalyst (at $1.54 \mathrm{~V}$ ). dividing the $\mathrm{C}_{\mathrm{dl}}$ with the $\mathrm{C}_{\mathrm{S}}$ [27]. The accelerated stability measurements were performed by potential cycling between $1.0 \mathrm{~V}$ and $1.7 \mathrm{~V}$ versus RHE with a sweep rate of $50 \mathrm{mV} \mathrm{s}^{-1}$. After cycling, the resultant electrode was used for polarization curves with a sweep rate of $2 \mathrm{mV} \mathrm{s}^{-1}$. Long-term durability test was carried out under a constant voltage. The pure $\mathrm{IrO}_{2}$ and $\mathrm{Ir} / \mathrm{C}(20 \mathrm{wt} \%)$ inks were loaded on a glassy carbon electrode (surface area: $0.196 \mathrm{~cm}^{2}$ ), the loading mass is $0.25 \mathrm{mg}_{\mathrm{Ir}} \mathrm{cm}^{-2}$ and $0.1 \mathrm{mg}_{\mathrm{Ir}} \mathrm{cm}^{-2}$, respectively.

\subsection{Calculation methods}

All the density functional theory (DFT) calculations were using Vienna Ab-initio Simulation Package (VASP). The spin-polarized projector augmented wave (PAW) projectors and the Perdew-BurkeErnzerhof (PBE) functional of generalized gradient approximation (GGA) was applied to describe the electronic structures of materials. In this regard, the adsorption energies of oxygen intermediates on the stable (110) crystal surface of a rutile $\mathrm{IrO}_{2}$ has been systematically studied. The cutoff energy was set as $450 \mathrm{eV}$. The convergence thresholds were set as $1 \times 10^{-4} \mathrm{eV} /$ atom for the energy, and atomic relaxation was performed until all components of the residual forces were less than $3 \times 10^{-2} \mathrm{eV} / \AA$. For $\left(\operatorname{Ir}_{0.7} \mathrm{Ni}_{0.15} \mathrm{Co}_{0.15}\right) \mathrm{O}_{2}$ model, we replaced Ir atoms with $\mathrm{Co}$ and $\mathrm{Ni}$ atoms in the $(2 \times 2 \times 2)$ supercell. Before further calculate, the unit cell of model $\mathrm{IrO}_{2}$ was completely relaxed and the lattice constants was optimized. This was done to allow for symmetry breaking, as well as other interactions along this axis, which were observed for multiple geometries. In our calculations, we explored the four-electron path using the computational hydrogen electrode (CHE) model under an external potential of $1.23 \mathrm{~V}$.

\section{Results and discussion}

To obtain the uniform nanoporous structure of np- $\mathrm{Ir}_{70} \mathrm{Ni}_{30-\mathrm{x}} \mathrm{Co}_{\mathrm{x}}$, the $\mathrm{Ni}$ and Co were selectively dissolved from $\operatorname{Ir}_{3} \mathrm{Ni}_{97-\mathrm{x}} \mathrm{Co}_{\mathrm{x}}(\mathrm{x}=0,50,97)$ precursor alloys by the electrochemical corrosion in a $\mathrm{HCl}$ solution at the designed potential (see Section 2). X-ray diffraction (XRD) patterns of the $\mathrm{Ir}_{3} \mathrm{Ni}_{97-\mathrm{x}} \mathrm{Co}_{\mathrm{x}}(\mathrm{x}=0,50,97)$ precursor alloy ribbons are shown in Fig. S1, the three diffraction peaks are assigned as (111), (200), and (220) diffractions of a face centered-cubic (fcc) phase, respectively. Since the amount of Ir is low $(\sim 3$ at $\%)$ in the precursor alloy, positions of the three diffraction peaks are very close to those of pure Ni (JCPDS No.04-0850) or Co (JCPDS No.15-0806). After dealloying, the XRD diffraction peaks of the samples (Fig. S2) moved to lower angles, which locate between diffraction the peaks of pure Ir (JCPDS No.65-1686), and $\mathrm{Ni} / \mathrm{Co}$, indicating the significant alloy nature of the products [28]. The morphology of the as-prepared np- $\mathrm{Ir}_{70} \mathrm{Ni}_{30-\mathrm{x}} \mathrm{Co}_{\mathrm{x}}$ MWs was examined by utilizing field emission scanning electron microscopy (SEM). 
a

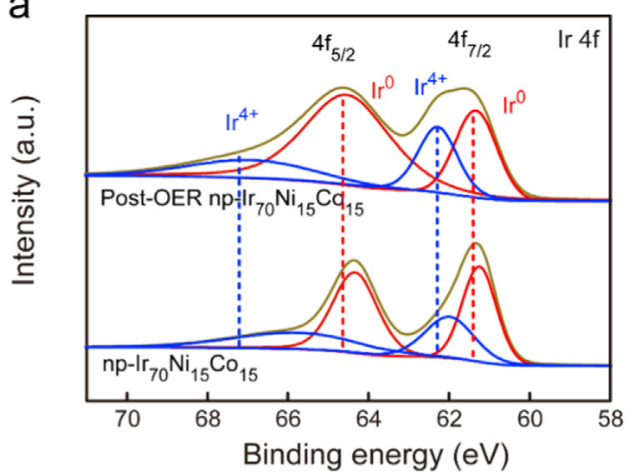

C
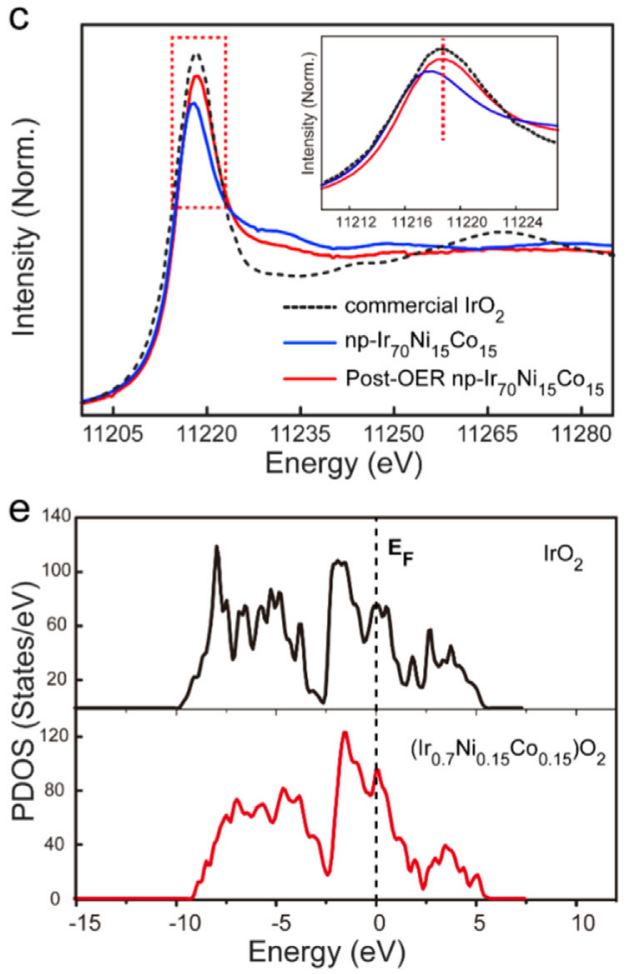

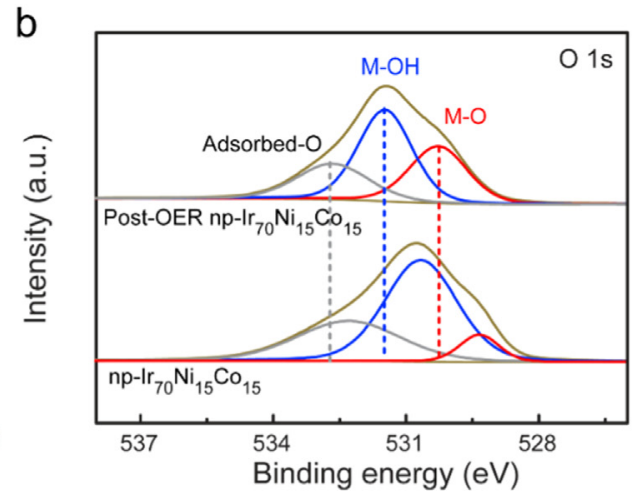

d

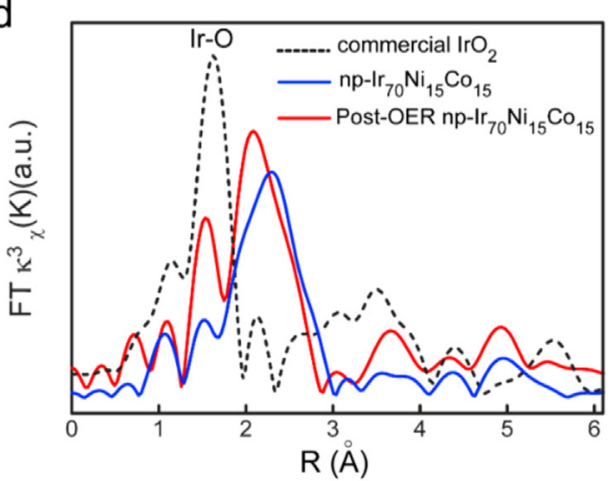

$f$

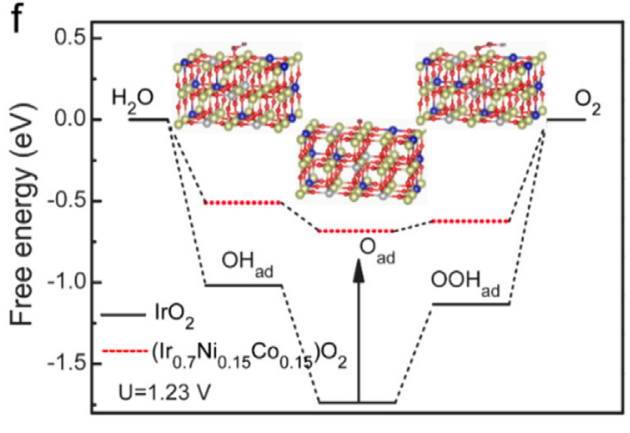

Reaction Path

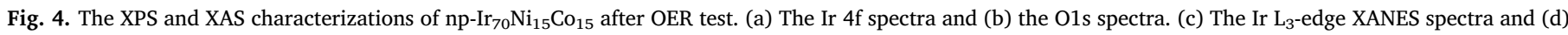

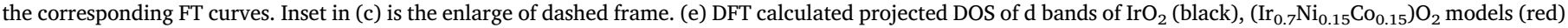
with corresponding Fermi level by dash lines. (f) DFT calculations of the free energy diagram for OER process on $\mathrm{IrO}_{2}$ and $\left(\mathrm{Ir}_{0.7} \mathrm{Ni}_{0.15} \mathrm{Co}_{0.15}\right) \mathrm{O}_{2}$.

As revealed in Fig. $1 \mathbf{a}$ and Fig. S3a and S3b, the np- $\mathrm{Ir}_{70} \mathrm{Ni}_{30-\mathrm{x}} \mathrm{Co}_{\mathrm{x}}$ alloy displays a well-connected grains and an aligned 3D microwires structure, with a length of each microwire $\sim 10 \mu \mathrm{m}$ (inset of Fig. 1a). The corresponding energy dispersive X-ray spectroscopy (EDS) analysis further provides a chemical composition of np- $\mathrm{Ir}_{70} \mathrm{Ni}_{30-\mathrm{x}} \mathrm{Co}_{\mathrm{x}}$ (Fig. S4). It is worth noting that the np- $\mathrm{Ir}_{70} \mathrm{Ni}_{30}, \mathrm{np}-\mathrm{Ir}_{70} \mathrm{Co}_{30}$ and np- $\mathrm{Ir}_{70} \mathrm{Ni}_{15} \mathrm{Co}_{15}$ display a similar specific surface area of $12-15 \mathrm{~m}^{2} \mathrm{~g}^{-1}$ under same preparation conditions (Fig. S5). Transmission electron microscopy (TEM) images of $n p-\mathrm{Ir}_{70} \mathrm{Ni}_{30-\mathrm{x}} \mathrm{Co}_{\mathrm{x}}(\mathrm{x}=0,15,30)$ further exhibit a uniform bicontinuous nanoporous architecture composed of interconnective metallic ligaments ( $\sim 5 \mathrm{~nm}$ ) (Fig. 1 b and Figs. S3c and 3d). The selected-area electron diffraction (SAED) pattern (inset of Fig. 1b) exhibits obvious polycrystalline rings, demonstrating the nanocrystalline nature of the np- $\mathrm{Ir}_{70} \mathrm{Ni}_{15} \mathrm{Co}_{15}$ microwires. The bicontinuous nanoporous architectures with visible lattice fringes also clearly presented by high-angle annular dark field-scanning TEM (HAADF-STEM) image (Fig. 1c). Lattice distance in np-Ir ${ }_{70} \mathrm{Ni}_{15} \mathrm{Co}_{15}$, measured from fast Fourier transformation (FFT) of HAADF-STEM image (Fig. 1d) is $0.22 \mathrm{~nm}$, which is indexed as the (111) plane of fcc Ir-Co-Ni alloy phase [29]. The chemical homogeneity of the nanoporous alloy is verified by scanning TEM- energy-dispersive X-ray spectroscopy (EDS) (Fig. 1e).
The well matched distributions of Ir, Ni and Co in the elemental mappings suggest the uniform chemistry of the heterogeneous nanoporous structure.

The surface chemical composition and valence state information of the np- $\mathrm{Ir}_{70} \mathrm{Ni}_{30-\mathrm{x}} \mathrm{Co}_{\mathrm{x}}$ are studied by X-ray photoelectron spectroscopy (XPS). The Ir $4 \mathrm{f}$ spectrum of $n p-\mathrm{Ir}_{70} \mathrm{Ni}_{30-\mathrm{x}} \mathrm{Co}_{\mathrm{x}}(\mathrm{x}=0,15,30)$ are fitted with four peaks with the binding energies of 61.1, 61.9, 64.2, and $65.8 \mathrm{eV}$, corresponding to $\mathrm{Ir}^{0} 4 \mathrm{f}_{7 / 2}, \mathrm{Ir}^{4+} 4 \mathrm{f}_{7 / 2}, \mathrm{Ir}^{0} 4 \mathrm{f}_{5 / 2}$, and $\mathrm{Ir}^{4+} 4 \mathrm{f}_{5 / 2}$ peaks (Fig. 2a), respectively, which indicate the coexistence of $\operatorname{Ir}^{0}$ and $\mathrm{Ir}^{4+}$ in the np- $\mathrm{Ir}_{70} \mathrm{Ni}_{30-\mathrm{x}} \mathrm{Co}_{\mathrm{x}}[30]$. More importantly, the Ir $4 \mathrm{f}$ has a positive shift in the np- $\mathrm{Ir}_{70} \mathrm{Ni}_{15} \mathrm{Co}_{15}$ samples, suggesting a higher oxidation state of Ir. Fig. $2 \mathbf{b}$ shows the Ni 2p XPS spectrum of np- $\mathrm{Ir}_{70} \mathrm{Ni}_{30}$ ${ }_{\mathrm{x}} \mathrm{Co}_{\mathrm{x}}(\mathrm{x}=0,15)$ mainly divided into $\mathrm{Ni} 2 \mathrm{p}_{3 / 2}$ and $\mathrm{Ni} 2 \mathrm{p}_{1 / 2}$. The binding energies of $853.5,855.9$ and $861.2 \mathrm{eV}$ are attributed to metallic $\mathrm{Ni}$ $(853.5 \mathrm{eV})$ and to the oxidized $\mathrm{Ni}$ species $(855.9$ and $861.2 \mathrm{eV})$, respectively the well-screened and poorly screened peak [31]. The Co $2 p$ XPS spectrum of $n p-\operatorname{Ir}_{70} \mathrm{Ni}_{30-\mathrm{x}} \mathrm{Co}_{\mathrm{x}}(\mathrm{x}=15,30)$ also exhibits three main characteristic peaks, which corresponding to metallic $\mathrm{Co}(777.5 \mathrm{eV})$ and to oxidized Co (781.2 and $785.5 \mathrm{eV}$ ) (Fig. 2c). It is worth noting that metallic Ni and Co are presented in np- $\mathrm{Ir}_{70} \mathrm{Ni}_{15} \mathrm{Co}_{15} \mathrm{MWs}$.

$\mathrm{X}$-ray absorption spectroscopy (XAS) measurements are performed 
to identify oxidation state and local atomic and electronic structure of Ir species in the $n p-\mathrm{Ir}_{70} \mathrm{Ni}_{15} \mathrm{Co}_{15}$. Fig. $2 \mathbf{d}$ shows the intensity of white line of the normalized X-ray absorption near-edge structure (XANES) spectrum at the Ir $\mathrm{L}_{3}$-edge of $\mathrm{np}-\mathrm{Ir}_{70} \mathrm{Ni}_{15} \mathrm{Co}_{15}$ is higher than that of Ir foil, but lower than the commercial $\mathrm{IrO}_{2}$, indicating the raised local coordination structure of Ir species and the coexistence of $\operatorname{Ir}^{0}$ and higher valence Ir species [32]. The corresponding $\mathrm{k}^{3}$-weighted EXAFS spectra of Ir $\mathrm{L}_{3}$-edge is shown in Fig. 2e. As shown in Fig. 2f, the Fourier transform (FT) curve of the Ir $\mathrm{L}_{3}$-edge for $\mathrm{np}-\mathrm{Ir}_{70} \mathrm{Ni}_{15} \mathrm{Co}_{15}$ in $\mathrm{R}$ space is obviously different from the standard reference samples, indicating a different arrangement of Ir atoms. The main distinct peak $(2.2 \AA)$ is shorter than Ir-Ir bond ( $2.52 \AA)$ in Ir foil but longer than that of Ir-O bond $(1.62 \AA)$ in $\mathrm{IrO}_{2}$, which indicates the formation of $\mathrm{Ir}-\mathrm{Co} / \mathrm{Ni}$ coordination in the alloy, and it matches well with the XRD results. Similar results are also observed in previously reported Ir-Co [33] and Ir$\mathrm{Ni}$ alloy [34]. The XANES of nickel and cobalt are both close to those of $\mathrm{Ni}$ and Co foil references (Fig. S6a and 6c), while the spectral differences mainly result from minor saturation effects due to the fluorescence yield detection mode. Here, the metal nature of both $\mathrm{Ni}$ and $\mathrm{Co}$ shown by XANES differs from that shown by XPS results, where both metal and oxides are found, mainly due to the bulk and surface sensitive detection depth difference of these two methods. In the FT-EXAFS results as shown in Fig. S6b and 6d, the main peaks $\sim 2.2 \AA$ correspond to the nearest-neighbor Ni-Ni and Co-Co bond distance [35].

The OER properties of the Ir-based nanoporous catalysts are investigated with a three-electrode system in acidic electrolyte. Before the lineal sweep voltammetry (LSV) test, the catalysts as self-standing electrodes were activated via cyclic voltammetry (CV) scanning from 1.0 to $1.7 \mathrm{~V}$ versus Reversible Hydrogen Electrode (RHE) at a sweep rate of $50 \mathrm{mV} \mathrm{s}^{-1}$. Fig. 3a shows the linear polarization curves of np$\mathrm{Ir}_{70} \mathrm{Ni}_{30-\mathrm{x}} \mathrm{Co}_{\mathrm{x}}(\mathrm{x}=0,15,30)$ in $0.1 \mathrm{M} \mathrm{HClO}_{4}$ electrolyte at the scan rate of $2 \mathrm{mV} \mathrm{s}^{-1}$, together with a commercial $\mathrm{IrO}_{2}$ and $\mathrm{Ir} / \mathrm{C}$ catalyst as the benchmark. The addition of $\mathrm{Ni}$ and Co significantly enhances catalysis of Ir. The np- $\mathrm{Ir}_{70} \mathrm{Ni}_{15} \mathrm{Co}_{15}$ yields the highest OER activities with an exceptionally low overpotential of $220 \mathrm{mV}$ at the current density of $10 \mathrm{~mA} \mathrm{~cm}^{-2}$, which was $13,22,90$ and $92 \mathrm{mV}$ less than that of np$\mathrm{Ir}_{70} \mathrm{Ni}_{30}, \mathrm{np}-\mathrm{Ir}_{70} \mathrm{Co}_{30}, \mathrm{IrO}_{2}$, and $\mathrm{Ir} / \mathrm{C}$ respectively. Furthermore, the mass activity of $n p-\mathrm{Ir}_{70} \mathrm{Ni}_{15} \mathrm{Co}_{15}$ is also little higher than that of other Irbased catalyst as shown in Fig. S7. The specific activity is obtained from the current density (overpotential @ $270 \mathrm{mV}$ ) normalized by the electrochemical active surface area (ECSA), derived from the electrochemical double-layer capacitance $\left(\mathrm{C}_{\mathrm{dl}}\right)$ measured by a cyclic voltammetry (CV) method (Fig. S8). The np- $\mathrm{Ir}_{70} \mathrm{Ni}_{15} \mathrm{Co}_{15}$ MWs electrode shows the highest specific activity of $0.25 \mathrm{~mA} \mathrm{~cm}^{-2}$, which is approximately 2.5 times higher than that of commercial $\mathrm{IrO}_{2}$ (inset of Fig. 3a). The significant distinction in OER performance between the binary and the trimetal catalysts is tentatively originated from the alloying effect. The Tafel slope is a kinetic parameter to gain deeper understanding of the intrinsic reaction mechanism of OER. Fig. $3 \mathbf{b}$ shows that the Tafel slope of $\mathrm{np}-\mathrm{Ir}_{70} \mathrm{Ni}_{15} \mathrm{Co}_{15}$ is $44.1 \mathrm{mV}$ per decade $\left(\mathrm{mV} \mathrm{dec}^{-1}\right)$, which is smaller than that of the commercial $\mathrm{IrO}_{2}\left(56.4 \mathrm{mV} \mathrm{dec}^{-1}\right)$. More interestingly, as shown in Fig. $3 \mathbf{c}$ and Table $\mathrm{S} 1$, the np- $\mathrm{Ir}_{70} \mathrm{Ni}_{15} \mathrm{Co}_{15}$ shows superior OER activity compared to other available Ir-based catalysts under acid conditions. Electrochemical impedance spectroscopy (EIS) of the np$\mathrm{Ir}_{70} \mathrm{Ni}_{30-\mathrm{x}} \mathrm{Co}_{\mathrm{x}}(\mathrm{x}=0,15,30)$ electrodes further confirm that the Ir-based trimetal alloy with $3 \mathrm{~d}$ transition metal contribute to a lower internal resistance and a faster charge transfer for low onset potential and high OER kinetics (Fig. S9). The durability of np- $\mathrm{Ir}_{70} \mathrm{Ni}_{15} \mathrm{Co}_{15}$ and commercial $\mathrm{IrO}_{2}$ was evaluated by using $\mathrm{CV}$ cycles and chronoamperometry technique. As presented in Fig. 3d, the linear polarization curve of np$\mathrm{Ir}_{70} \mathrm{Ni}_{15} \mathrm{Co}_{15}$ retained the initial performance with a slight decay $(\sim 13 \mathrm{mV})$ after 3000 cycles, suggesting that the extraordinary longterm stability for OER in acidic electrolyte. The chronoamperometry test of np- $\mathrm{Ir}_{70} \mathrm{Ni}_{15} \mathrm{Co}_{15}$ at $1.45 \mathrm{~V}$ versus RHE shows continuous stability for $24 \mathrm{~h}$ with no sign of decay (Fig. 3e). On the contrary, the commercial $\mathrm{IrO}_{2}$ powder has an obviously current decay after a continuous electrolysis at a constant potential for less than $4 \mathrm{~h}$. Besides the harsh acidic environment, the degradation may be ascribed to the peeling of electrocatalysts from the glass carbon electrode during the long-term OER process. Moreover, we examined the np- $\mathrm{Ir}_{70} \mathrm{Ni}_{15} \mathrm{Co}_{15}$ MWs electrode under XRD, XPS, SEM, and TEM observation after chronoamperometry testing in acidic media (Fig. S10-S12). The composition and nanoporous structure of alloy are well retained after the stability measurement, again verifying the excellent stability in acidic environment. The dissolution behaviors of $\mathrm{Ir}, \mathrm{Ni}$ and $\mathrm{Co}$ in electrolyte were analyzed by inductively coupled plasma-optical emission spectrometry (ICP-OES) (Fig. S13). The negligible amount of Ir leaching into the electrolyte is observed in $24 \mathrm{~h}$ for the np- $\mathrm{Ir}_{70} \mathrm{Ni}_{15} \mathrm{Co}_{15}$ catalyst. The $\mathrm{Ni}$ and Co concentration in electrolyte gradually reached $\sim 1.85 \mathrm{mg} \mathrm{L}^{-1}$ within $10 \mathrm{~h}$ and did not increase significantly after the following $14 \mathrm{~h}$, further demonstrating the excellent corrosion resistance and long-term stability of the np- $\mathrm{Ir}_{70} \mathrm{Ni}_{15} \mathrm{Co}_{15}$ catalyst. Additionally, the chronopotentiometry test of $n$ - $-\mathrm{Ir}_{70} \mathrm{Ni}_{15} \mathrm{Co}_{15}$ electrode in $0.1 \mathrm{M} \mathrm{HClO}_{4}$ solutions at a current density of $10 \mathrm{~mA} \mathrm{~cm}{ }^{-2}$ shows outstanding stability for $24 \mathrm{~h}$ without obvious degradation (Fig. S14).

In addition to the acidic solution, $\mathrm{np}-\mathrm{Ir}_{70} \mathrm{Ni}_{15} \mathrm{Co}_{15}$ also have highly active toward OER in neutral and basic solution (Fig. S15). At the current density of $10 \mathrm{~mA} \mathrm{~cm}^{-2}$, the overpotentials are as low as 290 and $190 \mathrm{mV}$, together with small Tafel slopes of 63.5 and $57.9 \mathrm{mV}$ $\mathrm{dec}^{-1}$, in the neutral and basic solutions, respectively. It is worth noting that such high catalytic activities in basic and neutral media are comparable and even superior to best OER catalysts reported in the literature (Table S2 and Table S3). Additionally, $\mathrm{np}-\mathrm{Ir}_{70} \mathrm{Ni}_{15} \mathrm{Co}_{15}$ shows excellent stability in both media (Fig. S15). Overall, these results unambiguously demonstrate that $\mathrm{np}-\mathrm{Ir}_{70} \mathrm{Ni}_{15} \mathrm{Co}_{15}$ is a highly versatile and efficient OER electrocatalyst in a wide $\mathrm{pH}$ range (pH 0-14), which is very similar to the commercial $\mathrm{IrO}_{2}$ catalyst but has better corrosion resistance in the acidic solutions.

To understand the origins of the outstanding catalytic activities and durability of $\mathrm{np}-\mathrm{Ir}_{70} \mathrm{Ni}_{15} \mathrm{Co}_{15}$, we elaborately characterized the np$\mathrm{Ir}_{70} \mathrm{Ni}_{15} \mathrm{Co}_{15}$ with XPS, HAADF-STEM, and XAS after OER test in $0.1 \mathrm{M}$ $\mathrm{HClO}_{4}$ electrolyte. As shown in Fig. 4 a, the positive shift of $\mathrm{Ir}_{4 f_{7 / 2}}$ peak from $60.5 \mathrm{eV}$ corresponding to metallic Ir to $61.7 \mathrm{eV}$, typically assigned to $\operatorname{Ir}^{\mathrm{IV}}$ [36]. Similar to Ir, the metallic state of Ni and Co nearly disappeared and transformed into high state is present in Fig. S16. Simultaneously, an increase in the contribution from lattice oxygen $(530.1 \mathrm{eV}) \mathrm{O} 1 \mathrm{~s}$ spectra is observed after the OER proceeds, which is indicative of the growth of the oxide on the surface of metallic Ir (Fig. 4b). The above XPS phenomena indicated that the Ir can be oxide to high state $\mathrm{IrO}_{\mathrm{x}}$ species. The TEM and HAADF-STEM also confirms that the Ir oxide species are restructured on the surface of np$\mathrm{Ir}_{70} \mathrm{Ni}_{15} \mathrm{Co}_{15}$ after OER (Fig. S17), which benefit to the stability of catalyst [37]. As shown in Fig. 4c and inset picture, the intensity of the white line peak of the normalized XANES spectrum of the post-OER np$\mathrm{Ir}_{70} \mathrm{Ni}_{15} \mathrm{Co}_{15}$ has a positive shift and higher than the initial np$\mathrm{Ir}_{70} \mathrm{Ni}_{15} \mathrm{Co}_{15}$, indicating that the valence of Ir species was increased [32]. The corresponding FT curve further confirms the oxidation of local coordination environment of Ir atoms from the strong peak of Ir-O (1.5 $\AA$ ) bond (Fig. 4d). However, the XANES curves of Ni K-edge slightly shift to a lower energy is directly observed after OER (Fig. S6a), indicating the oxidation state in the samples is reduced. The increase of a shoulder peak at $7716 \mathrm{eV}$ in Fig. S6c indicated that Co of np$\mathrm{Ir}_{70} \mathrm{Ni}_{15} \mathrm{Co}_{15}$ has a low-spin square-planar configuration, compared to the high-spin octahedral configuration in $\mathrm{CoO}$ [35]. These phenomena can also be verified in Fig. S6b and $6 \mathrm{~d}$ which the shoulder peak of Ni-O (1.5 $\AA$ ) and Co-O (1.2 $\AA$ ) bond was disappeared. We supposed that the results is due to the self-reconstruction of Ir migration from the bulk to the surface layer in an acidic electrolyte [38]. Based on the above discussion, we conclude that, the surface Ir species with high valence and low-coordination structure as real active site can promote OER performance $[39,40]$.

Density functional theory (DFT) calculations are carried out to gain 
insights into the fundamental mechanisms of the outstanding OER catalysis of $\mathrm{Ir}_{70} \mathrm{Ni}_{30-\mathrm{x}} \mathrm{Co}_{\mathrm{x}}$. Fig. $4 \mathbf{e}$ showed the projected DOS (PDOS) of $\mathrm{IrO}_{2}$ and the $\mathrm{Ir}_{70} \mathrm{Ni}_{15} \mathrm{Co}_{15}$ models using the general gradient approximation (GGA) calculation. The bimetallic doped models electron density at the Fermi level changed to a narrow shape, which will improve surface activity of catalyst and proceed the electron-proton charge exchange with a fast adsorption and desorption process [41]. Previous studies indicated that the OER activities of transition metal compounds are mainly evaluated by the energetics of the intermediates $\left({ }^{*} \mathrm{OH},{ }^{*} \mathrm{O}\right.$, and $\left.{ }^{*} \mathrm{OOH}\right)$ on the catalyst surfaces [30]. The $\mathrm{IrO}_{2}$ system exhibits that the ${ }^{*} \mathrm{OH}$ formation $\left(\Delta G^{*} \mathrm{OH}=-1.018 \mathrm{eV}\right)$ is the rate-determining step (Fig. $4 \mathbf{f}$ and Table S4). The $\left(\mathrm{Ir}_{0.7} \mathrm{Ni}_{0.15} \mathrm{Co}_{0.15}\right) \mathrm{O}_{2}$, from which it is found that the binding energy of $* \mathrm{O}$ reduced from -1.737 to $-0.684 \mathrm{eV}$ and the binding energy of * $\mathrm{OOH}$ increased from -0.623 to $-1.135 \mathrm{eV}$ relative to the $\mathrm{IrO}_{2}$ system (Fig. 4f). The decrease of in binding energy are accompanied with a remarkable decrease of free energy for the ${ }^{*} \mathrm{OOH}$ formation $\left(\Delta G^{*} \mathrm{OOH}=-0.623 \mathrm{eV}\right)$ and the ${ }^{*} \mathrm{O}$ formation $\left(\Delta G_{* \mathrm{O}}=-0.684 \mathrm{eV}\right)$, which is regarded as the rate-determining step in the $\left(\mathrm{Ir}_{0.7} \mathrm{Ni}_{0.15} \mathrm{Co}_{0.15}\right) \mathrm{O}_{2}$ system. As expected, therefore, the $\left(\operatorname{Ir}_{0.7} \mathrm{Ni}_{0.15} \mathrm{Co}_{0.15}\right) \mathrm{O}_{2}$ catalyst can considerably lower the activation barrier relative to its monometal counterpart. The above results clearly indicate that these synergistic effect of alloying Ir with $3 \mathrm{~d}$ transition metals can effectively modulate the free energies and binding energies of the intermediates towards an optimal energetics value to promote the OER process.

\section{Conclusion}

In summary, we have successfully developed a new nanoporous $\mathrm{Ir}_{70} \mathrm{Ni}_{30-\mathrm{x}} \mathrm{Co}_{\mathrm{x}}$ alloy microwires catalyst toward high-efficiency OER in acidic solutions by general dealloying method. The binder-free np$\mathrm{Ir}_{70} \mathrm{Ni}_{15} \mathrm{Co}_{15}$ catalyst exhibits the highest catalytic activity among all reported $\mathrm{IrO}_{2}$-based and $\mathrm{RuO}_{2}$-based catalysts toward OER in acidic solutions with a low overpotential $\left(220 \mathrm{mV} @ \eta=10 \mathrm{~mA} \mathrm{~cm}^{-2}\right)$ and low Tafel slope of $44.1 \mathrm{mV}$ per decade. The excellent performance is attributed to the nanoporous structure and the alloying effect, which promote the permeation of electrolyte, accelerate the transportation of electrons. The XAS results acquired on synchrotron radiation demonstrated that the high valence Ir oxide species with low-coordination structure in $\mathrm{np}-\mathrm{Ir}_{70} \mathrm{Ni}_{15} \mathrm{Co}_{15}$ alloy are the real catalytic sites of OER process, leading to an enhanced OER activity and stability $[42,43]$. This work not only provides fundamental understandings of the correlation between surface activity and stability for OER catalysts, but also paves a new way to advanced electrocatalysts working in acidic media.

\section{Acknowledgment}

The authors gratefully acknowledge financial support by the National Natural Science Foundation of China (Grant No. 51771072), the Youth 1000 Talent Program of China and Fundamental Research Funds for the Central Universities. We thank Dr. Y. R. Lu and Prof. T. S. Chan in NSRRC for XAS measurements.

\section{Notes}

The authors declare no competing financial interest.

\section{Appendix A. Supporting information}

Supplementary data associated with this article can be found in the online version at doi:10.1016/j.nanoen.2019.02.020.

\section{References}

[1] J.A. Turner, Science 305 (2004) 972-974.

[2] N. Mahmood, Y. Yao, J.W. Zhang, L. Pan, X. Zhang, J.J. Zou, Adv. Sci. 5 (2018)
1700464.

[3] L. Tao, C.-Y. Lin, S. Dou, S. Feng, D. Chen, D. Liu, J. Huo, Z. Xia, S. Wang, Nano Energy 41 (2017) 417-425.

[4] C. Mo, J. Jian, J. Li, Z. Fang, Z. Zhao, Z. Yuan, M. Yang, Y. Zhang, L. Dai, D. Yu, Energy Environ. Sci. 11 (2018) 3334-3341.

[5] L. Xu, Q. Jiang, Z. Xiao, X. Li, J. Huo, S. Wang, L. Dai, Angew. Chem. Int. Ed. 55 (2016) 5277-5281.

[6] N.T. Suen, S.F. Hung, Q. Quan, N. Zhang, Y.J. Xu, H.M. Chen, Chem. Soc. Rev. 46 (2017) 337-365.

[7] D. Chen, M. Qiao, Y.R. Lu, L. Hao, D. Liu, C.L. Dong, Y. Li, S. Wang, Angew. Chem. Int. Ed. 57 (2018) 8691-8696.

[8] S. Dou, L. Tao, R. Wang, S. El Hankari, R. Chen, S. Wang, Adv. Mater. 30 (2018) 1705850.

[9] T. Reier, H.N. Nong, D. Teschner, R. Schlögl, P. Strasser, Adv. Energy Mater. 7 (2017) 1601275.

[10] C. Spöri, J.T.H. Kwan, A. Bonakdarpour, D.P. Wilkinson, P. Strasser, Angew. Chem. Int. Ed. 56 (2017) 5994-6021.

[11] L.C. Seitz, C.F. Dickens, K. Nishio, Y. Hikita, J. Montoya, A. Doyle, C. Kirk, A. Vojvodic, H.Y. Hwang, J.K. Norskov, T.F. Jaramillo, Science 353 (2016) 1011-1014.

[12] Y. Pi, Q. Shao, P. Wang, J. Guo, X. Huang, Adv. Funct. Mater. 27 (2017) 1700886.

[13] T. Kwon, H. Hwang, Y.J. Sa, J. Park, H. Baik, S.H. Joo, K. Lee, Adv. Funct. Mater. 27 (2017) 1604688.

[14] T. Reier, Z. Pawolek, S. Cherevko, M. Bruns, T. Jones, D. Teschner, S. Selve, A. Bergmann, H.N. Nong, R. Schlogl, K.J. Mayrhofer, P. Strasser, J. Am. Chem. Soc. 137 (2015) 13031-13040.

[15] J. Park, Y.J. Sa, H. Baik, T. Kwon, S.H. Joo, K. Lee, ACS Nano 11 (2017) 5500-5509.

[16] H. Jin, Y. Hong, J. Yoon, A. Oh, N.K. Chaudhari, H. Baik, S.H. Joo, K. Lee, Nano Energy 42 (2017) 17-25.

[17] L. Zhao, Q. Cao, A. Wang, J. Duan, W. Zhou, Y. Sang, H. Liu, Nano Energy 45 (2018) $118-126$.

[18] S.M. Alia, S. Shulda, C. Ngo, S. Pylypenko, B.S. Pivovar, ACS Catal. 8 (2018) 2111-2120.

[19] Q. Lu, G.S. Hutchings, W. Yu, Y. Zhou, R.V. Forest, R. Tao, J. Rosen, B.T. Yonemoto, Z. Cao, H. Zheng, J.Q. Xiao, F. Jiao, J.G. Chen, Nat. Commun. 6 (2015) 6567.

[20] B. Jiang, Y. Guo, J. Kim, A.E. Whitten, K. Wood, K. Kani, A.E. Rowan, J. Henzie, Y. Yamauchi, J. Am. Chem. Soc. 140 (2018) 12434-12441.

[21] Y.W. Tan, H. Wang, P. Liu, C. Cheng, F. Zhu, A. Hirata, M. Chen, Adv. Mater. 28 (2016) 2951-2955.

[22] J. Erlebacher, J.A. Michael, A. Karma, N. Dimitrov, K. Sieradzki, Nature 410 (2001) 450-453.

[23] Y. Ding, M.W. Chen, J. Erlebacher, J. Am. Chem. Soc. 126 (2004) 6876-6877.

[24] L.Y. Chen, N. Chen, Y. Hou, Z.C. Wang, S.H. Lv, T. Fujita, J.H. Jiang, A. Hirata, M.W. Chen, ACS Catal. 3 (2013) 1220-1230.

[25] J. Snyder, T. Fujita, M.W. Chen, J. Erlebacher, Nat. Mater. 9 (2010) 904-907.

[26] Y. Liu, X. Liang, L. Gu, Y. Zhang, G.D. Li, X. Zou, J.S. Chen, Nat. Commun. 9 (2018) 2609.

[27] C.C. McCrory, S. Jung, J.C. Peters, T.F. Jaramillo, J. Am. Chem. Soc. 135 (2013) 16977-16987.

[28] H.J. Qiu, X. Shen, J.Q. Wang, A. Hirata, T. Fujita, Y. Wang, M.W. Chen, ACS Catal. 5 (2015) 3779-3785.

[29] J. Feng, F. Lv, W. Zhang, P. Li, K. Wang, C. Yang, B. Wang, Y. Yang, J. Zhou, F. Lin, G.-C. Wang, S. Guo, Adv. Mater. 29 (2017) 1703798.

[30] W. Sun, Y. Song, X.Q. Gong, L.M. Cao, J. Yang, Chem. Sci. 6 (2015) 4993-4999.

[31] F.M.Fd Groot, J. Electron Spectrosc. Related Phenom. 67 (1994) 529-622.

[32] Y. Zhang, C. Wu, H. Jiang, Y. Lin, H. Liu, Q. He, S. Chen, T. Duan, L. Song, Adv. Mater. 30 (2018) 1707522.

[33] P. Jiang, J. Chen, C. Wang, K. Yang, S. Gong, S. Liu, Z. Lin, M. Li, G. Xia, Y. Yang, J. Su, Q. Chen, Adv. Mater. 30 (2018) 1705324

[34] L. He, Y. Huang, X.Y. Liu, L. Li, A. Wang, X. Wang, C.-Y. Mou, T. Zhang, Appl. Catal. B-Environ. 147 (2014) 779-788.

[35] S.Z. Song, J. Zhou, X.Z. Su, Y. Wang, J. Li, L.J. Zhang, G.P. Xiao, C.Z. Guan, R.D. Liu, S.G. Chen, H.J. Lin, S. Zhang, J.Q. Wang, Energy Environ. Sci. 11 (2018) 2945-2953.

[36] T. Li, O. Kasian, S. Cherevko, S. Zhang, S. Geiger, C. Scheu, P. Felfer, D. Raabe, B. Gault, K.J.J. Mayrhofer, Nat. Catal. 1 (2018) 300-305.

[37] N. Danilovic, R. Subbaraman, K.C. Chang, S.H. Chang, Y. Kang, J. Snyder, A.P. Paulikas, D. Strmcnik, Y.T. Kim, D. Myers, V.R. Stamenkovic, N.M. Markovic, Angew. Chem. Int. Ed. 53 (2014) 14016-14021.

[38] Y. Pi, Q. Shao, X. Zhu, X. Huang, ACS Nano 12 (2018) 7371-7379.

[39] S. Geiger, O. Kasian, M. Ledendecker, E. Pizzutilo, A.M. Mingers, W.T. Fu, O. DiazMorales, Z.Z. Li, T. Oellers, L. Fruchter, A. Ludwig, K.J.J. Mayrhofer, M.T.M. Koper, S. Cherevko, Nat. Catal. 1 (2018) 508-515.

[40] A. Grimaud, A. Demortiere, M. Saubanere, W. Dachraoui, M. Duchamp, M.L. Doublet, J.-M. Tarascon, Nat. Energy 2 (2016) 16189.

[41] J. Su, R. Ge, K. Jiang, Y. Dong, F. Hao, Z. Tian, G. Chen, L. Chen, Adv. Mater. 30 (2018) 1801351.

[42] H.G. Sanchez Casalongue, M.L. Ng, S. Kaya, D. Friebel, H. Ogasawara, A. Nilsson, Angew. Chem. Int. Ed. 53 (2014) 7169-7172.

[43] X. Zheng, B. Zhang, P. De Luna, Y. Liang, R. Comin, O. Voznyy, L. Han, F.P. Garcia de Arquer, M. Liu, C.T. Dinh, T. Regier, J.J. Dynes, S. He, H.L. Xin, H. Peng, D. Prendergast, X. Du, E.H. Sargent, Nat. Chem. 10 (2018) 149-154. 


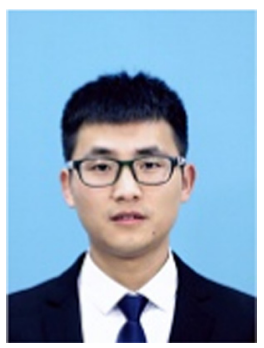

Yang Zhao is currently a Ph.D. student under the supervisor of Prof. Tan in College of Materials Science and Engineering in Hunan University. He received his B.S. in Huaihua University in 2014 and M.S. in Chongqing University in 2017. His current research focuses on 3D nanoporous alloy material synthesis and applications in electrocatalysis water splitting and carbon dioxide reduction.

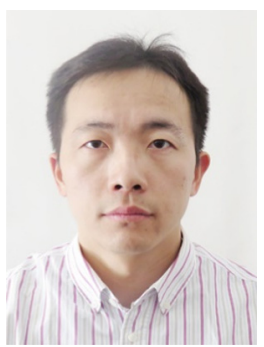

Min Luo is an associate professor in Physics department of Shanghai Polytechnic University, China. His research focuses on the structure, properties and mechanisms of nanomaterials by the DFT calculations.

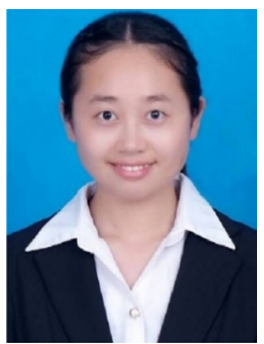

Shufen Chu received her bachelor's degree in Central South University in 2016. Now she is a Ph.D. student in College of Materials Science and Engineering in Shanghai Jiao Tong University, China. Her research interests focus on the development and characterization of 3D nanoporous materials for energy and environment related applications.

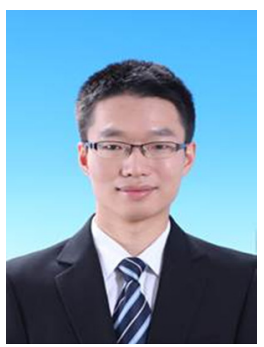

Ming Peng is an assistant professor of College of Materials Science and Engineering, Hunan University. He received his B.S. Degree from Wuhan University in 2011 and Ph.D Degree from Peking University in 2016. He is now working in Prof. Tan's group. The current research interest is the design and synthesis of porous functional materials and their application in electrochemical energy fields.

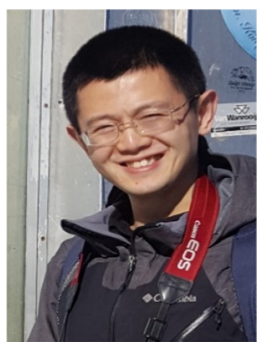

Boyang Liu received his Ph.D. degree in Chemistry from Utrecht University in 2017. After that, he joined in XSoLaS group in Stockholm University as a postdoctoral researcher. Currently, he is focusing on probing ultrafast surface chemical reaction by using X-ray free electron laser.

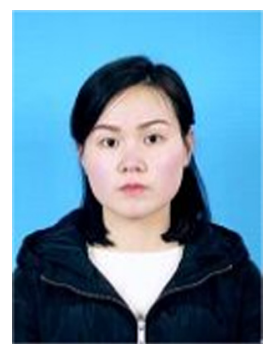

Qiuli Wu is currently a M.S. candidate under the supervisor of Prof. Tan in College of Materials Science and Engineering in Hunan University. She received her bachelor's degree in Henan Normal University, China in 2017. Her research interests mainly focus on preparation and application of nanoporous materials.

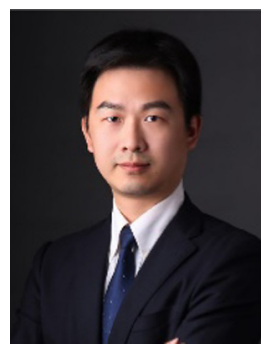

Pan Liu is an associate professor in Materials Science and Engineering department in Shanghai Jiao Tong University, China. His research focuses on the application of advanced electron microscopy to materials science. Particular interest goes to 3D nanoporous materials, nanostructured materials, 2D materials, and battery materials.

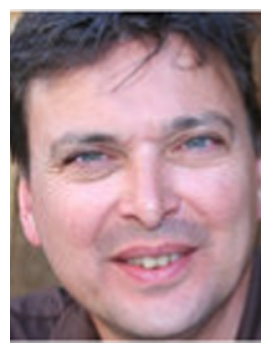

Frank M.F. De Groot is a full professor of Synchrotron and Theoretical Spectroscopy of Catalytic Nanomaterials in the Department of Chemistry at Utrecht University. His research interests focus on the theoretical and the experimental aspects of X-ray spectroscopy, including both fundamental studies and applications.

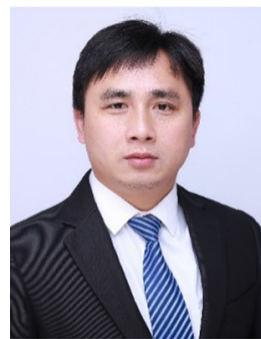

Yongwen Tan is a full professor in College of Materials Science and Engineering in Hunan University. He received his $\mathrm{Ph} . \mathrm{D}$. in college of Materials Science and Engineering in Shanghai Jiao Tong University, China. in 2013. Then, he joined the AIMR of Tohoku University as a research associate. His research focuses on synthesis and applications of $3 \mathrm{D}$ nanoporous materials. 